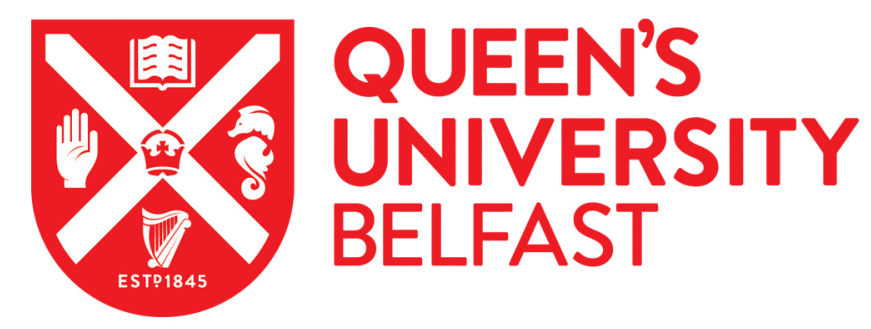

\title{
An improved clinical risk stratification system to better predict cancer specific mortality at diagnosis in primary non-metastatic prostate cancer
}

Gnanapragasm, V. J., Lophatananon, A., Wright, K. A., Muir, K. R., Gavin, A., \& Greenberg, D. C. (Accepted/In press). An improved clinical risk stratification system to better predict cancer specific mortality at diagnosis in primary non-metastatic prostate cancer. Poster session presented at 31st Annual EAU Congress, Munich, Germany.

Queen's University Belfast - Research Portal:

Link to publication record in Queen's University Belfast Research Portal

\section{General rights}

Copyright for the publications made accessible via the Queen's University Belfast Research Portal is retained by the author(s) and / or other copyright owners and it is a condition of accessing these publications that users recognise and abide by the legal requirements associated with these rights.

Take down policy

The Research Portal is Queen's institutional repository that provides access to Queen's research output. Every effort has been made to ensure that content in the Research Portal does not infringe any person's rights, or applicable UK laws. If you discover content in the Research Portal that you believe breaches copyright or violates any law, please contact openaccess@qub.ac.uk. 


\section{An improved clinical risk stratification system to better predict cancer specific mortality at diagnosis in primary}

non-metastatic prostate cancer.

Vincent J Gnanapragasam ${ }^{1 * \#}$, Artitaya Lophatananon ${ }^{2 *}$, Karen A Wright ${ }^{3}$, Kenneth R Muir ${ }^{4}$, Anna Gavin ${ }^{5}$ and David C Greenberg $^{3 *}$.

${ }^{1}$ Academic Urology Group, University of Cambridge, UK, ${ }^{2}$ Division of Health Sciences, University of Warwick UK, ${ }^{3}$ Public Health England, UK, ${ }^{4}$ Institute of Population Health, University of Manchester, UK ${ }^{5}$ Northern Ireland Cancer Registry, UK

\section{Introduction}

It is estimated that the number of new cancer diagnosis in the U alone will approach 70,000 per annum by 2030, Of this population over

ment for these men. The most widely used stratification system is the 3 strata $\mathrm{D}^{\prime} \mathrm{Amic}$ in outcomes (9-10). This development is particularly welcome as work from our own centre and others have shown significant grade inflation in contemporary cohors bus not

A novel approach to risk sub-stratification was recently reported in high-risk surgically treated prostate cancer groups could be identified by considering the number of prevalen high-risk factors an individual had.

In this current study we explored if this notion could be applied in other risk categories and in the context of predicting prognosis in changes in the pathological reporting system in the updated WHO guidelines 2016

Our goal was to test whether a new clinical risk stratification mode could be developed which would provide a better predictive model for

\section{Patients and methods}

Cohorts : Primary prostate cancers (ICD10 site: C61) diagnosed in residents of the East of England Cancer Network area between 2000 and 2010. Cases with any metastatic involvement were excluded. The with all components of diagnostic stage, primary and secondary and presenting PSA $(\mathrm{ng} / \mathrm{ml})$ as well as data on follow up and survival were included.The final primary cohort used for testing and training sets comprised 10,139 subjects with 789 prostate cancer deaths an 2610 overall deaths. To validate the results we sourced an avaliable 706 subjects with 43 prostate cancer deaths, 144 all cause deaths.

- Statistical analysis : Risk groups were initially assigned as low, intermediate and high-risk based on the UK (NICE) guidelines The pathological grade sum and clinical stage) were then used to substratify within each risk catesory and their assocition with prosta cancer specific mortality (PCSM). In addition we used the new ISU prognostic scores as a discriminator. Based on this we derived a new PCSM (Table 1). We then used a cross validation method to test ans for the cohort into 60\% ( $n=6026)$ as training set and $40 \%(n=4113)$ testing set. To compare survival differences between each risk group we applied a cox hazards model and the Log rank test with pair-wise assess poss. For visual companson we used kaplan-Meier plots. To assess prediction performance, the Harrell's concordance index ( $(\mathrm{C})$ include the potential influence of non-cancer deaths and cumulative incidence curves generated and compared between the risk groups
(SPSS statistics version 22, STATA/MP 12.1, R Commander plug-in EZR (Easy R) version 1.23 (1) and R version 3.0.1.

\begin{tabular}{|c|c|}
\hline $\begin{array}{c}\text { New risk } \\
\text { group }\end{array}$ & \begin{tabular}{c} 
Criteria \\
\hline 1
\end{tabular} \\
\hline 2 & Gleason 6 (Prognosic score 1) AND PSA A 10ng/mI AND Stage T1- \\
T2
\end{tabular}

Table 1 - Proposed New Prostate Cancer Risk Group criteria. system.

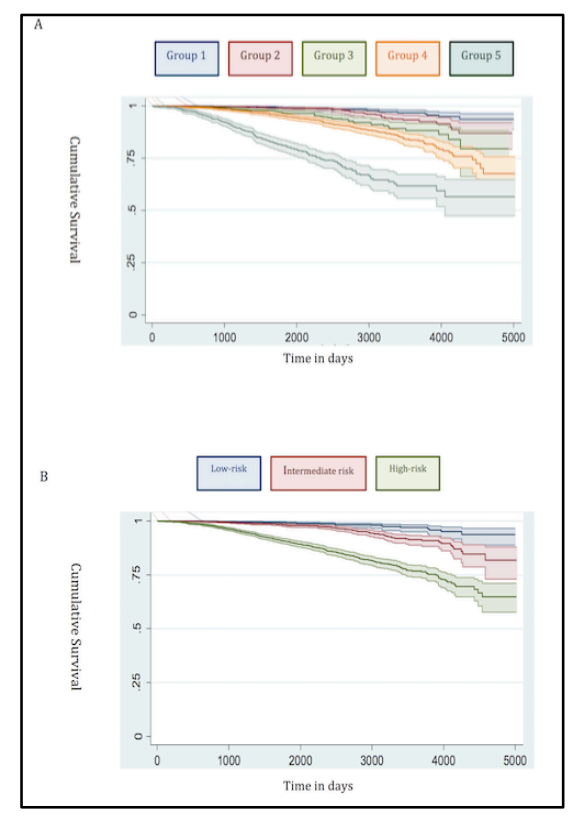

Fig 1 A: New risk criteria applied to training set. B: NICE risk groups applied to training set. Kaplan Meir curves and 95\% group ( $n=6026)$.

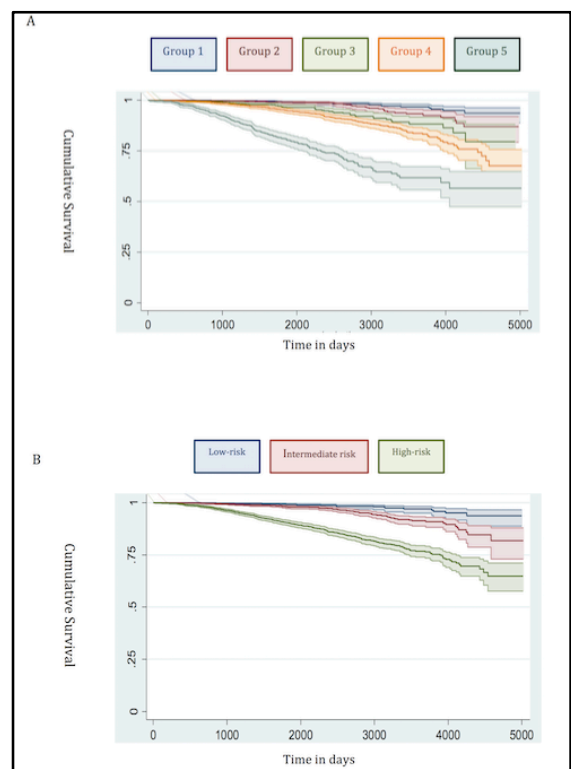
Fig 2 A: New risk criteria applied to testing set. B: NICE risk
groups applied to testing set. Kaplan Meir curves and $95 \%$ (n)

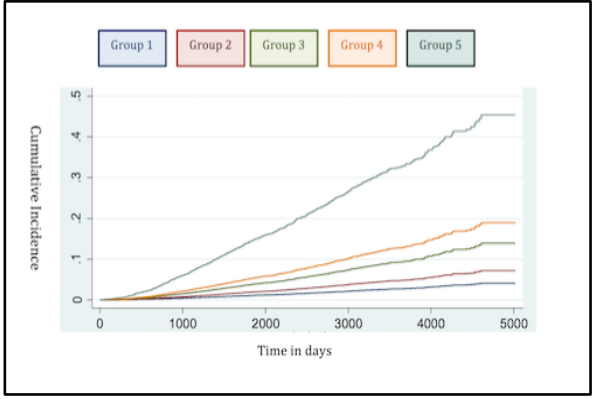

Fig 3: Cumulative incidence curve for the whole cohort to assess competing mortality risk in the new risk model.
$(n=10,139,789$ prostate cancer death, 1821 other causes)

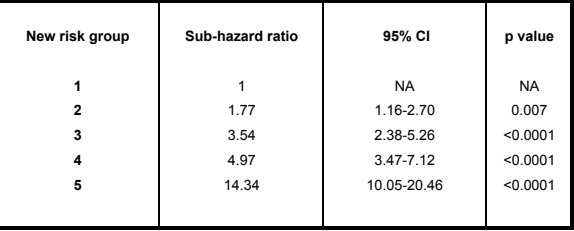

Table 2 - Competing risk regression analysis for the whole cohort $(n-10,139)$ including 789 prostate cancer deaths and
1821 other cause mortality Comparison of the groups is made with group 1 as the reference.

\begin{tabular}{|c|c|c|c|}
\hline Cohort (n) & $\begin{array}{c}\text { Prostate cancer } \\
\text { deaths }(\%)\end{array}$ & \multicolumn{2}{|c|}{$\begin{array}{c}\text { Concordance index (confidence } \\
\text { interval) } \\
\text { New Risk Group }\end{array}$} \\
\hline $\begin{array}{c}\text { Testing set (4113) } \\
\text { Full primary cohort } \\
(10139)\end{array}$ & $327(7.9 \%)$ & $0.67(0.64-0.69)$ & $0.75(0.72-0.77)$ \\
$\begin{array}{c}\text { Validation cohort } \\
\text { (1706) }\end{array}$ & $43(2.5 \%)$ & $0.69(0.68-0.77)$ & $0.76(0.74-0.77)$ \\
\hline
\end{tabular}

Table 3 - Concordance indices for prostate cancer specific mortality of the NICE risk criteria and the new risk group
criteria in testing and full sets as well as the validation cohort.

\section{Summary of Results}

- In the entire primary cohort there were 789 prostate cancer deaths within a median follow up of 6.9 years.

- In the training set the new risk system identified distinct subgroups with different risks of PCSM in pair-wise comparison
$($ p $<0.0001)$. Specifically, the new classification idention ( $p<0.0001)$. Specifically, he hew classification ident a very lonners with a low PCSM risk (Group 2 HR 1.62[0.97-2.75) and a further subgroup with an increased PCSM risk (Group 3, HR $3.35[2.04-5.59])(p<0.0001)$ (Figure 1).

High-risk cancers were also sub-classified by the new risk strata into a better and worse outcome group: Group 4 (HR 5.03 (Figure 1 ).

- These results were recapitulated in the testing set (Figure 2). - In competing risk regression, cumulative incidence curves and sub-hazard ratios continued to demonstrate a good - Compare to NICE the new risk tratication so demonstrated an improved prognostic concordance instem $0.75-0.76$ versus $0.67-0.69$ ( ( $p<0.0001)$. In an external cohort the new system achieved a concordance index of 0.83 (Table 3 ).

\section{Conclusion}

A novel and simple 5 strata risk classification system outof PCSM at diagnosis in men with primary non-metastatic prostate cancer. 